\title{
Clean, green flying machines
}

DOES FLYING COST THE EARTH?

Science Museum, London. Until 15 November 2008.

\section{Aircraft emissions show little sign of abating as the development of climate-friendly technologies struggles to keep pace with booming passenger numbers.}

Behemoths of the fossil fuel era greet visitors to London's Science Museum. Just inside the entrance, in Energy Hall, stands Thomas Newcomen's hulking steam engine, which started the industrial revolution and ran on coal. Two galleries in, hanging between nineteenth-century locomotives and a vertical stack of six classic cars, one of the world's first commercial airliners glowers from the ceiling.

It is a powerful symbol of modernity - its iconic status surely one reason the mere mention of slashing emissions from air travel draws so much anxiety. Aviation was the first economic sector to have its greenhouse emissions and promised technological innovations scrutinized in a special report of the Intergovernmental Panel on Climate Change (IPCC). Now the Science Museum takes up the same subject for one of the earliest in a series of climate change-related exhibitions.

So how bad is aviation for the planet? The show, Does Flying Cost the Earth?, starts by highlighting the importance of perspective in addressing this question. Three pie charts present the case. Concerned that your carbon consumption is out of control? Then worry about air travel: taking about two flights a year costs the average Briton 12 per cent of her individual carbon pie. Or worried about how governments propose to cut national and global emissions? Planes spew 6 per cent of the UK's carbon dioxide, but only 2 per cent of the world's. By 2050, that 2 per cent is expected to creep up to about 3 per cent.

This is where the exhibit first makes an inevitable compromise on thoroughness. Captions fail to make it clear that the pies show carbon dioxide only and omit other greenhouse gases. But partly because of those other gases and their intensified effects at high altitude, the IPCC estimated in 1999 that air travel accounted for roughly 3.5 per cent of the human-caused greenhouse effect in 1992, a figure predicted to climb to 5 per cent by 2050 , though with large uncertainty. More recently, the UK's Royal Commission on Environmental Pollution suggested the 5 per cent should be revised to 6-10 per cent. of aircraft emissions, which leads to a walk-through display of the green technology that could power future planes. Both have a high gee-whiz factor: I was delighted to learn that scientists at Lancaster University have recruited a network of condensation-trail spotters who gather data by staring at the sky daily, and to inspect models of nifty futuristic jets.

In exploring such technologies, the exhibition makes inspired use of facts and figures. Each innovation, from lightweight composite materials to hydrogen fuel, is rated in five categories: emission cuts, timescale to deployment,

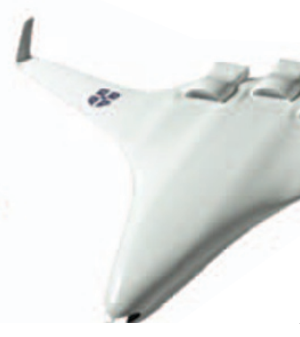

The 1935 Lockheed Electra (left), an early commercial airliner featuring a then-cutting-edge aluminium-alloy skin, overlooks the entrance to the Science Museum's exhibition of green aviation technology for the twenty-first century. Highly aerodynamic 'blended-wing' plane designs (right) may be seen on runways in 25 years. (Image credit: Left, Science Museum; Right, Jennie Hills/Science Museum. )

The impact of aircraft on our future climate will be determined by, among other factors, the combined warming effects of all greenhouse gases. Quoting percentages of carbon dioxide alone makes the numbers more digestible, perhaps - it's the count most familiar to eco-conscious apportioners of pie slices - but far less meaningful.

Stronger set-pieces follow. After an explanation of the greenhouse effect comes an excellent computer presentation on research into the impacts

$$
\text { cost, effort }
$$$$
\text { required, and }
$$
effect on passenger experience. Removing

rivets from plane surfaces, for example, can be done immediately at low cost but hardly cuts emissions. A new open-rotor engine yields deeper cuts but makes flights unpleasantly noisy and slow. Like those of baseball cards or characters in role-playing games, the statistics - listed on cards that can be picked up and passed around - are addictive to compare and analyze. Two important possible advances fall outside the scope of this green-tech survey, however: better air traffic control to cut emissions, and supersonic jets that would greatly worsen aviation's impacts.

A rudimentary video game near the exhibition's end sums up the situation at a visceral level. As air traffic increases in the future, players try to keep emissions down by installing green technologies in the hordes of planes multiplying on a touch-screen sky - an upgrade carried out by poking the icons to change their color and shape. The difficulty of the task lends a crude but memorable caveat to the exhibit's technological optimism.

Finally, the exhibition ventures into activism, inviting visitors to pledge to 
do their share against aviation emissions by supporting green policy, taking fewer flights or buying carbon offsets. A video display shows how many have taken each pledge, a great way to make people feel part of a concerned community. But the feel-good message that "collectively ... we can all make a difference" is undermined by the incomplete treatment of impacts earlier on. Make a difference between what -2 and 3 per cent of global emissions? By its end, the exhibit has offered some engaging glimpses of aviation's vanguard for climate science and engineering, but it hasn't satisfyingly answered the question in its title. It has the excuse that scientists and engineers are still working out that answer.
Published online: 12 June 2008

doi:10.1038/climate.2008.58

\section{Anna Barnett}

Anna Barnett is assistant editor and copy editor of Nature Reports Climate Change.

e-mail:a.barnett@nature.com

\title{
Full of hot air
}

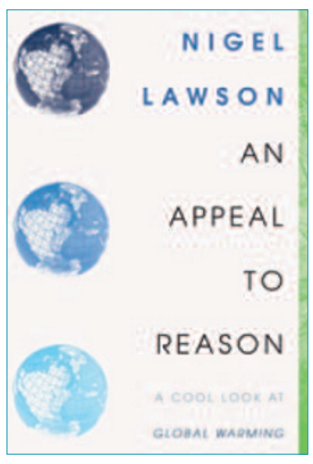

\section{AN APPEAL TO REASON: A COOL LOOK AT GLOBAL WARMING}

\author{
by Nigel Lawson \\ Duckworth Overlook: April 2008. 149pp. £9.99
}

\section{Far from being cool and rational, Nigel Lawson's offering on climate change is largely one of misleading messages.}

Although there remains uncertainty in many aspects of climate science, as in all science, over the past few years an overwhelming and well-founded acceptance has emerged, not only in the scientific community, but among the general public and in political arenas, that human activity, and in particular the burning of fossil fuels, is warming the planet. Far from the debate being over, with this awareness the discourse on climate change has largely moved from one of questioning the science to disputing what ought to be done about the problem.

Into this arena enters An Appeal to Reason by Nigel Lawson, former Chancellor of the UK Exchequer, who makes a call for "a cool look at global warming". Journeying through the science, politics, economics and ethics of climate change, Lawson challenges head-on the aspects of conventional wisdom that he believes to be flawed, and shines a light on what he interprets as spinning of rhetoric by the media and politicians.

Promised as a "rare breath of intellectual rigour" and a "hard headed examination of the realities" of climate change, this offering is neither cool nor rational. Although Lawson makes some worthwhile critiques of energy policy, presenting an argument for carbon taxation over carbon trading, for example, and gives some insights into how a deal on mitigating warming involving both developed and developing nations might work, his book is largely one of misleading messages.

The first of these is his questioning of the reality of human-caused global warming itself. Early in the book, showing a surprising ignorance of elementary statistical analysis, Lawson takes the record of global average temperature in the first seven years of this century as evidence that the scientists must have it wrong. By themselves, these years show no significant increase in temperature, but they are warmer on average by almost $0.1{ }^{\circ} \mathrm{C}$ than the previous seven years. Even a casual inspection of the global record from 1970 shows two things: first a clear trend of about a $0.5^{\circ} \mathrm{C}$ increase over the past 30 years, and second a substantial year-to-year variability of the kind that is well known to climatologists and has been attributed to phases of the El Niño/La Niña phenomenon, a regular feature of the Pacific climate.

Lawson then challenges the carefully worded conclusion of the UN's Intergovernmental Panel on Climate Change that "most of the observed increase in global average temperatures since the mid-20th century is very likely due to the observed increase in anthropogenic greenhouse gas concentrations." He does this, not with any analysis of his own, but by listing some of the sources of uncertainty that are in any case thoroughly addressed by the IPCC. One wonders whether he has in fact read the panel's reports.

Moving on from his critique of the science of climate change, Lawson argues that even if global average temperature increased by about $3{ }^{\circ} \mathrm{C}$, such warming would be trivial, and even largely beneficial. But given that the difference in temperature between the middle of an ice age and the warm periods in between ice ages is only 5 or $6{ }^{\circ} \mathrm{C}$, an increase of $3{ }^{\circ} \mathrm{C}$, occurring over much shorter time periods - on the scale of centuries rather than millennia - is far from inconsequential. And although they receive extensive coverage in the IPCC reports, Lawson completely ignores some of the most serious impacts of global warming: namely the floods and droughts that are expected to become more frequent and more severe with even small rises in temperature.

Considering the potential for more climate extremes and sea level rise in the future, there are likely to be hundreds of 
millions of refugees from the world's most affected nations. Where could those people go in our increasingly crowded world? Lawson denies that there is any problem. He repeats a number of times his summary of the damage as the difference between people in the developing world being 8.5 times better off than they are now and the 9.5 times improvement that they would see in the absence of global warming. Sleight of hand with gross numbers of possible economic growth must not be allowed to hide the magnitude of the very real problems. The 2007 IPCC report makes it clear that the anticipated impacts of global warming will lead to tens or hundreds of millions of people suffering loss of resources, livelihoods and land.

But even if such impacts were likely, we cannot afford to address them, says Lawson. To stabilize atmospheric concentrations of greenhouse gases during this century, emissions would have to be substantially reduced from today's levels by mid-century. And because carbon dioxide emitted into the atmosphere remains there on average for around 100 years, there is an urgent need to begin reductions now. Lawson writes this off as being difficult, inconvenient and very costly. But both the International Energy Agency and Shell have recently presented scenarios of changes in energy generation and use by 2050 that show it would be feasible to move substantially towards achieving the emissions reductions required. How great, then, is the cost? The Stern Review on the Economics of Climate Change indicates that if we act quickly, this could be as little as a few per cent of GDP by 2050. Crucially, delayed action will increase the price tag, with the cost of doing nothing and paying to adapt to change much greater than that of early mitigation. Again, Lawson begs to differ, arguing that the financial burden of reducing emissions sharply would simply be unjustified in the face of scientific uncertainty.
Lawson, with rhetorical flourishes, addresses those of us who see more than a 'grain of truth' in global warming and wish to take responsible action towards its mitigation. He lumps us together with a motley mixture of those he labels as eco-fundamentalists or anti-globalization lobbyists. All of us are connected with what he calls a "mountain of nonsense" for which it appears the IPCC is responsible. May I urge Lord Lawson to espouse the cool reason and rigour for which he appears to be campaigning and respectfully suggest that he might begin with a course of reading of the IPCC reports.

Published online: 19 June 2008

doi:10.1038/climate.2008.60

\section{Sir John Houghton}

Sir John Houghton CBE, FRS is an Honorary Scientist at the Met Office Hadley Centre in the UK.

e-mail: john.houghton@jri.org.uk

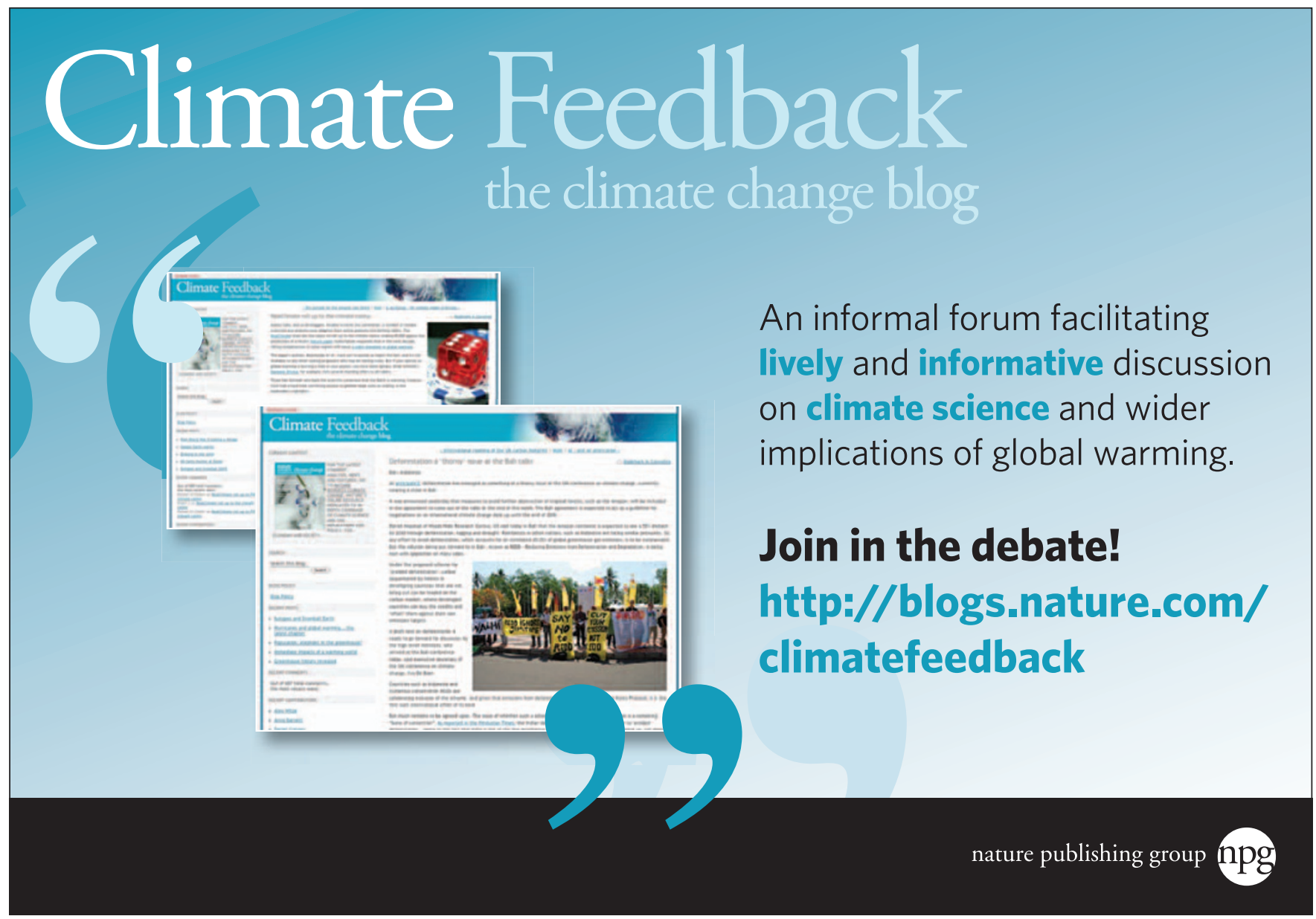

